\title{
EVALUATION OF ANALGESIC (IN VIVO) ACTIVITY OF ARIFLEX TABLET IN COMPARISON WITH DICLOFENAC AND ACECLOFENAC USING ACETIC ACID INDUCED WRITHING MODEL IN MICE
}

\author{
SANJAY NIPANIKAR ${ }^{1 *}$, CHITLANGE SS ${ }^{2}$ \\ ${ }^{1}$ Ari Healthcare Pvt. Ltd., Office No. 107, $1^{\text {st }}$ Floor, S. No. 1, World Trade Center, Tower One, Opp. EON SEZ, Kharadi, Pune, Maharashtra, \\ India. ${ }^{2}$ Padmashree Dr. D. Y. Patil Institute of Pharmaceutical Sciences and Research, Pimpri, Pune, Maharashtra, India. \\ Email: sanjay.n@arihealthcare.in \\ Received: 26 March 2021, Revised and Accepted: 17 June 2021
}

ABSTRACT

Objective: The present study was conducted to evaluate analgesic activity of Ariflex Tablet in comparison to Aceclofenac and Diclofenac Tablet.

Methods: Albino mice of either sex weighing 20-25 g were taken and divided into four groups with six animals in each group. Group 1 (Control Group) animals were starved overnight. Group 2 animals were orally administered with Diclofenac Tablet as Standard drug. Group 3 animals were orally administered with Aceclofenac Tablet as Standard drug and Group 4 Animals were orally administered with Ariflex Tablet. The test and standard drugs were orally administered with feeding needle after $1 \mathrm{~h}$ of injecting $1 \%$ acetic acid intraperitoneally in volume of $0.1 \mathrm{ml} / 10 \mathrm{~g}$ body weight. Writhing episodes were recorded for 30 min by counting the stretching.

Results: All the tested formulations possess analgesic activity in acetic acid induced writhing model. Aceclofenac possesses strong analgesic activity compared to other formulations tested. In Ariflex Tablet Group, the number of writhes was $120.6 \pm 41.4$. If compared to control group, the number of writhes was significantly less suggesting analgesic activity of Ariflex Tablet. Analgesic activity of Ariflex Tablet was close to that of Diclofenac Sodium.

Conclusion: It can be concluded that Ariflex Tablet possesses significant analgesic activity. Ariflex Tablet can be used in the management of Osteoarthritis, Rheumatoid arthritis, Gouty arthritis, Lumbago, Sciatica, and Spondylitis.

Keywords: Ariflex tablet, Aceclofenac and diclofenac tablet, Analgesic, Acetic acid induced writhing model.

(C) 2021 The Authors. Published by Innovare Academic Sciences Pvt Ltd. This is an open access article under the CC BY license (http://creativecommons.org/ licenses/by/4.0/) DOI: http://dx.doi.org/10.22159/ajpcr.2021v14i8.42188. Journal homepage: https://innovareacademics.in/journals/index.php/ajpcr

\section{INTRODUCTION}

Osteoarthritis (OA) is a Greek word, which is made by combination of words such as, "osteon" meaning bone and "arthron" meaning joint with the suffix "it is" for inflammation. $\mathrm{OA}$ is the most common form of arthritis. $\mathrm{OA}$ is estimated to be the eighth leading cause of disability in the world [1,2]. In India, $\mathrm{OA}$ is the most frequent joint disease with prevalence of $17 \%$ to $60.6 \%$ [2]. Furthermore, it is second most common rheumatological problem in India [3].

$\mathrm{OA}$ is a chronic degenerative joint disease characterized by loss of or injury to articular cartilage, sub-chondral thickening, and hypertrophy of bone and alterations of the synovial membrane and joint capsule [3]. In $\mathrm{OA}$, bone rubbing causes pain, swelling, and restricted range of motion at the affected joint. The joint may also lose its normal shape. In the normal adult, articular cartilage consists of a delicate system of cells and matrix proteins, which have the function of creating a viscoelastic tissue with high biomechanical stability and low friction. Articular cartilage remains stable, if the process of degeneration and regeneration of cells and matrix proteins occurs in equilibrium. Chondrocytes are the cartilage cells, which produce and maintain the cartilaginous matrix, which consists mainly of collagen and proteoglycans. The alteration of chondrocyte transplantation and degeneration of cartilage due to various triggering factors causes OA [4].

At present, very few underlying factors are known to cause OA. However, some common factors such as age, sex, obesity, genetics, bone density, smoking, and local factors including trauma are main contributors to the pathogenesis of OA. OA with no known cause is termed as primary $\mathrm{OA}$. It is mostly related to aging. Secondary OA results subsequent to another disease or condition. The above-mentioned factors initiate alterations in the equilibrium of cartilage formation and enhance degenerative cascade thus cause $\mathrm{OA}[1,3,4]$.

In general, $\mathrm{OA}$ is managed by symptomatic treatment methods such as use of pain killer and anti-inflammatory medications. Acetaminophen is considered to be the first-line therapy in the management of OA. Nonsteroidal anti-inflammatory drugs (NSAIDs) (selective and nonselective COX-2 inhibitors) are also commonly used for OA. Furthermore, the symptomatic slow acting drugs for $\mathrm{OA}$ such as diacerein, hyaluronic acid, and chondroitin sulfate are useful in OA management [5]. In OA, intra-articular corticosteroid injections are believed to be most effective in patients with evidence of inflammation, effusion, or both. Various other therapies such as transcutaneous nerve stimulation, thermal modalities, acupuncture, and surgery (including joint replacement) have also been used to treat OA. At present, though pharmacological, mechanical, and surgical interventions are used, there is no known cure for OA. Furthermore, above mentioned treatment options lead to many side effects and drawbacks. Thus, physicians and patients tend to move toward the use of alternative treatment methods [5-7].

Sandhigata Vata described under Vatavyadhi in Ayurveda can be correlated to OA. According to Ayurveda, Sandhi means joints and Vata has been considered the most important Dosha (humor) among the three Doshas. Thus, Sandhigata Vata means vitiated Vata residing at Sandhi. In Sandhigata Vata, vitiated Vata in joints causes severe pain, dryness, and obstructed joint movements. In Ayurveda, various local as well as oral treatment modalities have been used for the management of Sandhigata Vata. Various types of hot fomentations have been advocated as effective treatment measures. Local therapy includes massage with medicated oils such as Mahanarayan Taila, and Narayan Taila followed by hot fomentation, whereas the oral therapy mainly includes the use of Rasnadi Guggulu, Mahayogaraj guggulu, and Trayodashanga guggulu. 
Several plants such as Shallaki, Ashvagandha, Guggulu, Rasna, Nirgundi, Eranda, Guduchi, and Shunthi are also effectively used to treat OA [810].

Keeping in mind the basic concept of Ayurveda, Ari Healthcare Private Limited, has developed Ariflex tablet for effective management of various types of arthritis. Ariflex tablet contains Shallaki extract (Boswellia serrata) [11,12], Guggulu extract (Commiphora mukul) [13], Rasna extract (Pluchea lanceolata) [14], Ashvagandha extract (Withania somnifera) [15], Nirgundi extract (Vitex negundo) [16], Guduchi extract (Tinospora cordifolia) [17], Eranda extract (Ricinus communis) [18], and Shunthi extract (Zingiber officinale) [19].

In the present study, an attempt has been made to evaluate analgesic (in vivo) activity of Ariflex Tablet in comparison with oral Diclofenac sodium and Aceclofenac using acetic acid induced writhing model.

\section{METHODS}

Study site

The study was conducted at Padmashree Dr. D. Y. Patil Institute of Pharmaceutical Sciences and Research, Pimpri, Pune-411018.

\section{Ethical consideration and approval}

All laboratory animal handling and experimental procedures were performed in accordance with the CPCSEA guidelines (198/99/ CPCSEA) and study protocol. The Institutional Animal Ethics Committee (IAEC) of Padm. Dr. D. Y. Patil Institute of Pharmaceutical Sciences and Research, Pimpri, Pune - 18 has approved the study in the meeting held on December 31, 2014. The approved protocol number was DYPIPSR/ IAEC/14-15/P-04.

\section{Study drugs}

Study drugs used in the study were Diclofenac sodium, Aceclofenac, and Ariflex tablet. Drugs including Diclofenac sodium and Aceclofenac were purchased from market whereas Ariflex tablet was supplied by Ari Healthcare Private Limited Pune. The composition of Ariflex tablet are mentioned in Table 1.

\section{Drug material}

The material used for the study is shown in following Table 2 .

\section{Study animals}

Male Albino Mice of 3-4 weeks age and having weight between $20 \mathrm{~g}$ and $25 \mathrm{~g}$ were used in the study. The details are given in Table 3.

Table 1: Composition of Ariflex tablet Each Film Coated Tablet Contains:

\begin{tabular}{lll}
\hline Ingredients & Botanical Name & Quantity (mg) \\
\hline Shallaki Extract & B. serrata & $110 \mathrm{mg}$ \\
Guggulu Extract & C. mukul & $100 \mathrm{mg}$ \\
Rasna Extract & P. lanceolata & $65 \mathrm{mg}$ \\
Ashwagandha Extract & W. somnifera & $65 \mathrm{mg}$ \\
Nirgundi Extract & V. negundo & $60 \mathrm{mg}$ \\
Guduchi Extract & T. cordifolia & $55 \mathrm{mg}$ \\
Eranda Extract & R. communis & $50 \mathrm{mg}$ \\
Shunthi Extract & Z. officinale & $20 \mathrm{mg}$ \\
\hline
\end{tabular}

P. lanceolata: Pluchea lanceolata, W. somnifera: Withania somnifera, $V$. negundo: Vitex negundo, T. cordifolia: Tinospora cordifolia, R. communis: Ricinus communis, Z. officinale: Zingiber officinale, C. mukul: Commiphora mukul, B. serrate:

Boswellia serrate

Table 2: Materials used for the study

\begin{tabular}{ll}
\hline Material & Make \\
\hline Acetic Acid & Merck \\
Diclofenac Tablet & Novartis \\
Aceclofenac Tablet & Novartis \\
Ariflex Tablet & Ari Healthcare Private Limited Pune \\
\hline
\end{tabular}

Procurement of study animals

All animals were obtained from National Institute of Biosciences Pune. Animals were housed at standard laboratory conditions of temperature and $12 \mathrm{~h}$ light and $12 \mathrm{~h}$ dark cycle with free access to standard pellet diet and water.

\section{Study procedure}

Albino mice of either sex weighing 20-25 g were taken and divided into four groups with six animals in each group. Group 1 (Control Group) animals were starved overnight. Group 2 animals were orally administered with Diclofenac Tablet as Standard drug. Group 3 animals were orally administered with of Aceclofenac Tablet as Standard drug and Group 4 Animals were orally administered with Ariflex Tablet. The test and standard drugs were orally administered with feeding needle after $1 \mathrm{~h}$ of injecting 1\% acetic acid intraperitoneally in volume of $0.1 \mathrm{ml} / 10 \mathrm{~g}$ body weight. Writhing episodes were recorded for $30 \mathrm{~min}$ by counting the stretching.

\section{RESULTS}

- Animals in control group experienced more pain as evident from the results. The number of writhes in control group was $261 \pm 28.99$ $($ Mean \pm SEM)

- In Diclofenac group, the number of writhes was $95.4 \pm 11.81$ (Mean \pm SEM). If compared to control group, the number of writhes was significantly less suggesting analgesic activity of Diclofenac

- The number of writhes in Aceclofenac group was $33.8 \pm 11.53$ (Mean $\pm S E M$ ). If compared to control group, the number of writhes was significantly less suggesting strong analgesic activity of Aceclofenac

- In Ariflex Tablet Group, the number of writhes was $120.6 \pm 41.4$. If compared to control group, the number of writhes was significantly less suggesting analgesic activity of Ariflex Tablet. The details are presented in Table 4 and Fig. 1.

\section{DISCUSSION}

$\mathrm{OA}$ is a chronic degenerative joint disease characterized by loss or injury of articular cartilage, sub-chondral thickening, hypertrophy of bone, and alterations in the synovial membrane and joint capsule [3].

Chondrocytes are the cartilage cells, which produce and maintain the cartilaginous matrix that is mainly composed of collagen and proteoglycans. The alteration of chondrocyte transplantation and degeneration of cartilage due to various triggering factors causes OA [3].

Goals of treatment for OA include pain alleviation and improving the function of the joint to mitigate the reduction in activity. Various pharmacological and non-pharmacological treatments are used in $\mathrm{OA}$. But being unable to modify the natural course or progression of disease, no treatment has proven curative in nature. Role of both pharmacological and non-pharmacological modalities of treatment has been emphasized in guidelines provided for non-surgical management of OA [20].

Table 3: Animals used for the study

\begin{tabular}{lllll}
\hline Species & $\begin{array}{l}\text { Age in } \\
\text { weeks }\end{array}$ & $\begin{array}{l}\text { Weight/ } \\
\text { Size in } \mathbf{g}\end{array}$ & Gender & $\begin{array}{l}\text { Numbers } \\
\text { to be used }\end{array}$ \\
\hline Albino Mice & $3-4$ & $20-25$ & Male & 15 \\
\hline
\end{tabular}

Table 4: No. of writhes (Mean \pm SEM) for different groups

\begin{tabular}{ll}
\hline Groups & No. of writhes (Mean \pm SEM) \\
\hline Control & $261 \pm 28.99$ \\
Diclofenac sodium & $95.4 \pm 11.81^{* *}$ \\
Aceclofenac & $33.8 \pm 11.53^{* *}$ \\
Ariflex Tablet & $120.6 \pm 41.4^{*}$ \\
\hline
\end{tabular}




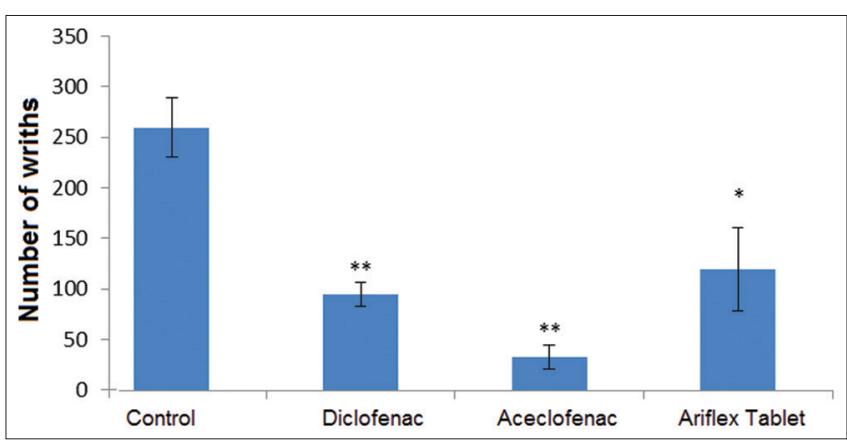

Fig. 1: Analgesic activity of Ariflex Tablet. Data are expressed as Mean \pm SEM of $n=6$ observations. All treatments were compared with control (ANOVA followed by Dunnett's test) *p<0.05, ${ }^{* *} \mathbf{p}<0.01$

Exercise, weight reduction, use of various supportive devices and education is encouraged in initial stage of OA. Use of acetaminophen, NSAIDs and nutritional supplements such as glucosamine and chondroitin sulfate are suggested for symptom management. Acetaminophen is considered as first-line drug for pain relief. If pain relief is inadequate with acetaminophen, NSAIDs especially, selective COX-II inhibitors are recommended in appropriate dosage. If NSAIDs fail to provide sufficient pain relief and risk of adverse effects of NSAIDs such as gastric bleeding is anticipated, use of intra-articular corticosteroid is advised. Use of the steroidal injection is limited to 2-3 times a year owing to greater chances of progressive cartilage damage through repeated injections in weight-bearing joints [20].

Invasive treatments such as arthroscopic lavage, cartilage debridement, osteotomy, and lastly total joint replacement are considered only when all above conservative treatments fail to provide symptom relief [20].

Various other therapies such as transcutaneous nerve stimulation, thermal modalities, acupuncture, and surgery (including joint replacement) have also been used to treat 0 A. Although pharmacological, mechanical and surgical interventions are used, there is no known cure for OA. Furthermore, above mentioned treatment options lead to many side effects and drawbacks on their long-term irrational use.

Acetaminophen overdose leads to hepatotoxicity which is common and potentially fatal incident [21]. Numerous prospective studies have identified prevalence of $15-20 \%$ for gastric ulcers and $5-8 \%$ for duodenal ulcers after 12 weeks of therapy of NSAIDs [22]. Numerous epidemiologic studies have demonstrated that the risk of a significant GI complication is increased in patients on chronic NSAID therapy to a rate of $1-4 \%$ per year [22]. Corticosteroid drugs do not independently cause ulcer disease. The use of these drugs in conjunction with NSAIDs, however, increases the risk of a gastrointestinal (GI) event approximately two-fold [22]. NSAIDs are also associated with adverse effects such as renal toxicity, cardiovascular events, increased blood pressure, and deterioration of congestive heart disease [23]. Skin atrophy, Hyperglycemia, Electrolyte abnormalities, Weight gain/moon facies, Purpura, Acne/hirsutism, GI bleed, ulcer, Fatty liver, Osteoporosis, etc., are side effects associated with the use of corticosteroids [24].

Ari healthcare Pvt. Ltd. has conceptualized and developed formulation, that is, Ariflex tablet for the treatment of OA, Rheumatoid arthritis, Gouty arthritis, Lumbago, Sciatica, and Spondylitis.

To establish analgesic activity of Ariflex tablet, before the clinical trials, this experimental study was conducted. In this study, evaluation of analgesic activity (in vivo) of Ariflex tablet in comparison with Diclofenac Tablet and Aceclofenac Tablet using Acetic acid induced writhing model was done. From the results, it is clear that all the formulations tested possess analgesic activity in acetic acid induced writing model. Aceclofenac being selective COX II inhibitor possesses strong analgesic activity among tested formulations. After Aceclofenac, the less number of writes was found in Diclofenac sodium group. The observed results are in line with the published literature. Ariflex tablet being herbal formulation, showed less analgesic activity as compared to Diclofenac Sodium and Aceclofenac. When compared to control group Ariflex Tablet possesses significant analgesic activity. The analgesic activity of Ariflex Tablet was close to that of Diclofenac Sodium.

Ingredients of Ariflex Tablet such as Shallaki (B. serrata) [26], Nirgundi (V. negundo) $[34,35]$, and Shunthi (Z. officinale) $[38,39]$ possess analgesic activity. Few ingredients of formulation have central as well as peripheral analgesic activity [34]. Few ingredients reduce the secretion of prostaglandins and also provide relief from the symptoms of pain by inhibition of COX enzyme [38]. Few ingredients have pain suppressing activity possibly mediated through PG synthesis inhibition and through the opioid receptors $[34,35,38]$. Thus, the observed significant analgesic activity of Ariflex Tablet could be the results of synergetic activities of various analgesic herbs present in the formulation.

\section{CONCLUSION}

It can be concluded that Ariflex Tablet possesses significant analgesic activity. Ariflex Tablet can be used in the management of OA, Rheumatoid arthritis, Gouty arthritis, Lumbago, Sciatica, and Spondylitis.

\section{AUTHORS CONTRIBUTION}

All authors have contributed equally to conceptualize study design, study conduct, acquisition, analysis, interpretation of data and also drafting, and final approval for the manuscript.

\section{CONFLICT OF INTEREST}

Nil.

\section{AUTHORS FUNDING}

Ari Healthcare Private Limited Pune.

\section{REFERENCES}

1. Hochberg MC, Altman RD, April KT, Benkhalti M, Guyatt G, McGowan J, et al. American college of rheumatology 2012 recommendations for the use of nonpharmacologic and pharmacologic therapies in osteoarthritis of the hand, hip, and knee. Arthritis Care Res 2012;64:465-74

2. Radha MS, Gangadhar MR. Prevalence of knee osteoarthritis patients in Mysore city, Karnataka. Int J Rec Sci Res 2015;6:3316-20.

3. Mahajan A, Verma S, Tandon V. Osteoarthritis. JAPI 2005;53:634-41.

4. Tallheden T, Bengtsson C, Brantsing C, Carlsson L, Peterson L, Brittberg $\mathrm{M}$, et al. Proliferation and differentiation potential of chondrocytes from osteoarthritic patients. Arthritis Res Ther 2005;7:560-8.

5. Scheinfeld N. A comprehensive review and evaluation of the side effects of the tumor necrosis factor alpha blockers etanercept, infliximab and adalimumab. J Dermatol Treat 2004;15:280-94.

6. Kongtharvonskul J, Anothaisintawee T, McEvoy M, Attia J, Woratanarat P, Thakkinstian A. Efficacy and safety of glucosamine, diacerein, and NSAIDs in osteoarthritis knee: A systematic review and network meta-analysis. Eur J Med Res 2015;20:24.

7. Tascioglu F, Armagan O, Tabak Y, Corapci I, Oner C. Low power laser treatment in patients with knee osteoarthritis. Swiss Med Wkly 2004; $134: 254-8$.

8. Long L, Soeken K, Ernst E. Herbal medicines for the treatment of osteoarthritis: A systematic review. Rheumatology 2001;40:779-93.

9. Sawarkar G, Sawarkar P. Prevention and management of osteoarthritis. Int J Res Ayurveda Pharm 2013;4:454-8.

10. Akhtar B, Mahto RR, Dave AR, Shukla VD. Clinical study on Sandhigata Vata w.s.r. to osteoarthritis and its management by panchatikta ghrita guggulu. Ayu 2010;31:53-7.

11. Cao H, Yu R, Choi Y, Zhang H, Xiang W, Lee D, et al. Discovery of cyclooxygenase inhibitors from medicinal plants used to treat inflammation. Pharmacol Res 2010;61:519-24

12. Alam M, Khan H, Samiullah L, Siddique KM. A review on phytochemical and pharmacological studies of Kundur (Boswellia 
serrata roxb ex colebr.)-a Unani drug. J Appl Pharm Sci 2012;2:148-56.

13. Shishodia S, Aggarwal B. Guggulsterone inhibits NF-B and I B kinase activation, suppresses expression of anti-apoptotic gene products, and enhances apoptosis. J Biol Chem 2004;279:47148-58.

14. Srivastava P. Chemical Standardization of Some Anti-inflammatory Rasayana Plants Used in Indian System of Medicine. Lucknow: Department of Chemistry University of Lucknow; 2013. p. 2-10.

15. Gacche R, Shaikh R, Pund M, Deshmukh R. Cyclooxygenase inhibitory, cytotoxicity and free radical scavenging activities of selected medicinal plants used in Indian traditional medicine. Pharmacogn J 2011;3:57-64.

16. Chattopadhyay P, Hazarika S, Dhiman S, Upadhyay A, Pandey A, Karmakar S, et al. Vitex Negundo inhibits cyclooxygenase-2 inflammatory cytokine-mediated inflammation on carrageenan-induced rat hind paw edema. Pharmacogn Res 2012;4:134-7.

17. Philip S, Tom G, Vasumathi AV. Evaluation of the anti-inflammatory activity of Tinospora cordifolia (Willd.) miers chloroform extract-a preclinical study. J Pharm Pharmacol 2018;70:1113-25.

18. Luseba D, Elgorashi EE, Ntloedibe DT, Staden JV. Antibacterial, antiinflammatory and mutagenic effects of some medicinal plants used in South Africa for the treatment of wounds and retained placenta in livestock. South Afr J Bot 2007;73:378-83.

19. van Breemen RB, Tao Y, Li W. Cyclooxygenase-2 inhibitors in ginger (Zingiber officinale). Fitoterapia 2011;82:38-43.

20. Samson DJ, Grant MD, Ratko TA, Bonnell CJ, Ziegler KM, Aronson N. Treatment of primary and secondary osteoarthritis of the knee. Evid Rep Technol Assess 2007;157:1-157.

21. Dhingra M, Nain P, Nain J, Malik M. Hepatotoxicity v/s hepatoprotective agents-a pharmacological review. Int Res J Pharm 2011;2:31-7.

22. Bjorkman DJ. Current status of nonsteroidal anti-inflammatory drug (NSAID) use in the United States: Risk factors and frequency of complications. Am J Med 1999;107:3-8.

23. Sostress C, Gorgallo CJ, Lanas A. Nonsteroidal anti-infl ammatory drugs and upper and lower gastrointestinal mucosal damage. Arthritis Res Ther 2013;15:S3.

24. Aletaha D, Smolen JS. Laboratory testing in rheumatoid arthritis patients taking disease-modifying antirheumatic drugs: Clinical evaluation and cost analysis. Arthritis Rheum 2002;47:181-8.

25. Sharma SK, Goyal N. Biological studies of the plants from genus Pluchea. Ann Biol Res 2011;2:25-34.
26. Singh GB, Bani S, Singh S. Toxicity and safety evaluation of boswellic acids. Phytomedicine 1996;3:87-90.

27. Sharma JN, Sharma JN. Comparison of the anti-inflammatory activity of Commiphora mukul (an indigenous drug with those of phenylbutazone and ibuprofen in experimental arthritis induced by mycobacterial adjuvant. Arzneimittel Forschung 1977;27:1455-57.

28. Singh BB, Mishra LC, Vinjamury SP, Aquilina N. The effectiveness of Commiphora mukul for osteoarthritis of the knee: An outcomes study. Alternat Ther Health Med 2003;9:74-9.

29. Arya D, Patni V. Microprogagation of Pluchea lancelata (oliver and Hiren,)-a potent antiarthritic medicinal herb. Int J Med Arom Plants 2013;3:55-60.

30. Sumantran VN, Kulkarni A, Boddul S, Chinchwade T, Koppikar SJ, Harsulkar A, et al. Chondroprotective potential of root extracts of Withania somnifera in osteoarthritis. J Biosci 2007;32:299-307.

31. Rasool M, Varalakshmi P. Immunomodulatory role of Withania somnifera root powder on experimental induced inflammation: An in vivo and in vitro study. Vasc Pharmacol 2006;44:406-10.

32. Upadhyay AK, Kumar K, Kumar A, Mishra HS. Tinospora cordifolia (Willd.) Hook. F. and Thoms. (Guduchi)-validation of the ayurvedic pharmacological through experimental and clinical studies. Int $\mathrm{J}$ Ayurveda Res 2010;1:112-21.

33. Vishwanathan AS, Basavaraju R. A review on Vitex negundo L.-a medicinally important plant. EJBS 2010;3:30-42.

34. Dharmasiri MG, Jayakody A, Galhena G, Liyanage SS. Anti- inflammatory and analgesic activities of mature fresh leaves of Vitex negundo. J Ethnopharmacol 2003;87:199-206.

35. Gupta M, Mazumder UK, Bhawal SR. CNS activity of Vitex negundo Linn., in Mice. Indian J Exp Biol 1999;37:143-6.

36. Apaya KL, Chichioco-Hernandez CL. Xanthine oxidase inhibition of selected Philippine medicinal plants. J Med Plants Res 2011;5:289-92.

37. Devi PR, Kumari SK, Kokilavani C. Effect of Vitex negundo leaf extract on the free radicals scavengers in complete Freund's adjuvant induced arthritic rats. Indian J Clin Biochem 2007;22:143-7.

38. Srivastava KC, Mustafa T. Ginger (Zingiber officinale) in rheumatism and musculoskeletal disorders. Med Hypotheses 1992;39:342-8.

39. Ojewole JA. Analgesic, antiinflammatory and hypoglycaemic effects of ethanol extract of Zingiber officinale (Roscoe) rhizomes (Zingiberaceae) in mice and rats. Phytother Res 2006;20:764-72. 